\title{
Oxygen surface exchange kinetics of erbia-stabilized bismuth oxide
}

\author{
Chung-Yul Yoo • Bernard A. Boukamp • \\ Henny J. M. Bouwmeester
}

Received: 5 July 2010 /Revised: 2 August 2010 / Accepted: 4 August 2010 /Published online: 1 September 2010

(C) The Author(s) 2010. This article is published with open access at Springerlink.com

\begin{abstract}
The surface oxygen exchange kinetics of bismuth oxide stabilized with $25 \mathrm{~mol} \%$ erbia (BE25) has been studied in the temperature and $p \mathrm{O}_{2}$ ranges $773-1,023 \mathrm{~K}$ and $0.1-$ $0.95 \mathrm{~atm}$, respectively, using pulse-response ${ }^{18} \mathrm{O}-{ }^{16} \mathrm{O}$ isotope exchange measurements. The results indicate that BE25 exhibits a comparatively high exchange rate, which is rate determined by the dissociative adsorption of oxygen. Defect chemical considerations and the observed $\mathrm{pO}_{2}{ }^{1 / 2}$ dependence of the rate of dissociative oxygen adsorption suggest electron transfer to intermediate superoxide ions as the rate determining step in surface oxygen exchange on BE25.
\end{abstract}

Keywords Isotopic exchange - Surface exchange kinetics · Solid electrolyte $\cdot$ Erbia-stabilized bismuth oxide

\section{Introduction}

Stabilized phases of $\delta-\mathrm{Bi}_{2} \mathrm{O}_{3}$ exhibit high oxide ion conductivity, which is related to a high polarizability of the bismuth ion and a high concentration of oxygen vacancies. In the parent cubic fluorite structure of $\delta-\mathrm{Bi}_{2} \mathrm{O}_{3}$,

\footnotetext{
C.-Y. Yoo • H. J. M. Bouwmeester $(\square)$

Inorganic Membranes, Membrane Technology Group,

Faculty of Science and Technology,

IMPACT and MESA+ Institute for Nanotechnology,

University of Twente,

Enschede 7500, AE, The Netherlands

e-mail: h.j.m.bouwmeester@tnw.utwente.nl

B. A. Boukamp

Inorganic Material Science Group,

Faculty of Science and Technology,

MESA+ Institute for Nanotechnology,

University of Twente,

Enschede 7500, AE, The Netherlands
}

$25 \%$ of the sites in the oxygen sublattice are vacant. Pure $\mathrm{Bi}_{2} \mathrm{O}_{3}$, however, transforms from the $\delta$-phase to the monoclinic $\alpha$-phase upon cooling below $\sim 1,003 \mathrm{~K}$ [1], showing a discontinuity in the ionic conductivity. The high temperature $\delta-\mathrm{Bi}_{2} \mathrm{O}_{3}$ phase can be stabilized to room temperature by the addition of rare earth oxides [2-6]. Erbia-stabilized bismuth oxide, $\left(\mathrm{Bi}_{2} \mathrm{O}_{3}\right)_{0.75}-\left(\mathrm{Er}_{2} \mathrm{O}_{3}\right)_{0.25}$, referred to as $\mathrm{BE} 25$, shows an ionic conductivity more than two orders of magnitude higher than that of conventional yttria-stabilized zirconia (YSZ), and has been investigated for its possible use as electrolyte for the low-temperature solid oxide fuel cell $[5,6]$.

Stabilization of $\delta-\mathrm{Bi}_{2} \mathrm{O}_{3}$ with isovalent $\mathrm{Er}_{2} \mathrm{O}_{3}$ preserves its high vacancy concentration albeit that, in general, a higher $\mathrm{Er}_{2} \mathrm{O}_{3}$ concentration results in a lower conductivity. At low $\mathrm{Er}_{2} \mathrm{O}_{3}$ concentrations and when operating at temperatures in the range $973-873 \mathrm{~K}$, the ionic conductivity is found to slowly decay with time due to transformation of the cubic phase into a rhombohedral phase. Kruidhof et al. [7] claimed that, when operating at $973 \mathrm{~K}$, a dopant concentration of at least $27.5 \% \mathrm{Er}_{2} \mathrm{O}_{3}$ is necessary to prevent phase separation. Jiang et al. [8] showed that even at a concentration of $40 \%$ $\mathrm{Er}_{2} \mathrm{O}_{3}$ the conductivity of phase-stabilized $\delta-\mathrm{Bi}_{2} \mathrm{O}_{3}$ is subject to aging due to gradual ordering of the anion sublattice when operating below $873 \mathrm{~K}$. In addition to phase and structural instability, the potential application of bismuth-containing electrolytes in solid oxide fuel cells (SOFCs) is regarded to be limited. The poor redox stability of the bismuth ion easily leads to decomposition (to metallic bismuth) of the bismuthcontaining electrolyte under the low oxygen partial pressures at the anode (fuel) side.

Compared with YSZ [9] and gadolinia-doped ceria [10], BE25 shows a remarkably high oxygen surface exchange rate. Current-voltage and impedance measurements of the properties of porous sputtered platinum and gold electrodes 
on BE25 show that the type of electrode material has little effect on the exchange current density, suggesting that for BE25 the entire electrolyte surface is active in the oxygen transfer reaction [11]. Reasonable agreement is found between the exchange current density from current-voltage measurements and the corresponding value calculated from data of ${ }^{18} \mathrm{O}-{ }^{16} \mathrm{O}$ isotopic exchange measurements. The very high oxide ion diffusivity in BE25 relative to the rate of surface exchange is found to create rather flat diffusion profiles in tracer diffusion experiments. For BE25, a critical thickness of $1.7 \mathrm{~cm}$ at $773 \mathrm{~K}$ and $1 \mathrm{~atm} p \mathrm{O}_{2}$ was deduced by Steele et al. [12] and of $10.3 \mathrm{~cm}$ at $923 \mathrm{~K}$ at $0.2 \mathrm{~atm} p \mathrm{O}_{2}$ by Capoen et al. [13] from data of ${ }^{18} \mathrm{O}-{ }^{16} \mathrm{O}$ isotopic exchange depth-profiling (IEDP) using secondary ion mass spectrometry (SIMS) analysis. The critical thickness, $L_{\mathrm{c}}$, reflects the length scale below which the surface exchange is rate limiting, and in tracer diffusion experiments is given by $L_{\mathrm{c}}=D^{*} / k_{\mathrm{s}}$, where $D^{*}$ is the tracer-diffusion coefficient and $k_{\mathrm{s}}$ the surface exchange coefficient [14]. The critical thickness at which oxygen diffusion and surface exchange determines equally the rate of oxygen permeation through BE25 was estimated by Bouwmeester et al. [15] to be $0.16 \mathrm{~mm}$ at $923 \mathrm{~K}$ and $0.09 \mathrm{~mm}$ at $1,083 \mathrm{~K}$. Note that the critical thickness deduced from oxygen permeation data is two to three orders magnitude lower than that from the tracer diffusion experiments. While in tracer experiments, $D^{*}$ governs the diffusion behavior, it is the ambipolar conductivity which controls the rate of oxygen permeation. The ambipolar conductivity in the solid electrolyte BE25 in usual ranges of oxygen partial pressure and temperature is determined by the partial $p$-type electronic conductivity, following a $p \mathrm{O}_{2}{ }^{1 / 4}$ power law dependence.

In this study, the surface exchange kinetics of BE25 is re-investigated using the pulse-response ${ }^{18} \mathrm{O}-{ }^{16} \mathrm{O}$ isotope exchange (PIE) technique. The method recently developed in our laboratory is based upon isotope analysis of an ${ }^{18} \mathrm{O}$ enriched gas phase pulse after passage of a continuousflow packed-bed microreactor loaded with the oxide powder [16]. The measurements are carried out under isothermal and iso- $p \mathrm{O}_{2}$ conditions. Since the method relies on gas phase analysis of the fractions of oxygen isotopomers with masses 36,34 , and $32\left({ }^{18} \mathrm{O}_{2},{ }^{16} \mathrm{O}^{18} \mathrm{O}\right.$, and ${ }^{16} \mathrm{O}_{2}$, respectively) also mechanistic information on the exchange reaction can be extracted from experiment contrary to, for example, data obtained by means of the IEDP-SIMS method.

\section{Experimental}

BE25 powder prepared by a conventional solid state reaction was provided by the Fraunhofer-Institut für Keramische Technologien und Systeme, IKTS (Institutsteil Hermsdorf). The as-received powder was uniaxially pressed at $30 \mathrm{MPa}$ into a disk, followed by cold isostatic pressing at $400 \mathrm{MPa}$. The disk was sintered at $1,123 \mathrm{~K}$ for $10 \mathrm{~h}$ in air, and crushed into a coarse powder. The fraction passing a $125 \mu \mathrm{m}$ stainless steel sieve was pre-annealed at $1,073 \mathrm{~K}$ for $10 \mathrm{~h}$ in air, and sieved again to remove formed agglomerates. Prior to pulse-response isotope exchange measurements, the powders were characterized by X-ray diffraction (Philips pananalitical PW1830), BET surface area (Micromeritics ASAP $2020 \mathrm{M}$ ), and particle size (Malvern Mastersizer 2000) measurements.

The pulse-response isotope exchange measurements were performed in the temperature and $p \mathrm{O}_{2}$ ranges $773-1,023 \mathrm{~K}$ and $0.1-0.95 \mathrm{~atm}$, respectively, using a continuous flow packed-bed micro-reactor. During the measurement, approximately $0.08 \mathrm{~g}$ of BE25 powder was loaded between two quartz wool plugs in the center of a quartz tubular microreactor with inner diameter $2 \mathrm{~mm}$. The length of the packedbed was typically $13 \mathrm{~mm}$. A ${ }^{16} \mathrm{O}_{2} / \mathrm{Ar}$ gas mixture was used as carrier gas with a flow rate $50 \mathrm{ml} / \mathrm{min}$ (STP). The response to ${ }^{18} \mathrm{O}_{2} / \mathrm{N}_{2}$ pulse $(500 \mu \mathrm{l})$, with the same $p \mathrm{O}_{2}$ as the carrier gas, passing through the reactor was analyzed by online mass spectrometry (Omni Star TM GSD 301 PfeifferVacuum) at the exit of the reactor as illustrated in Fig. 1. A six-port valve with sample loop was used for injection of the ${ }^{18} \mathrm{O}_{2} / \mathrm{N}_{2}$ pulse into the ${ }^{16} \mathrm{O}_{2} / \mathrm{Ar}$ carrier gas flow stream. Oxygen isotope gas was purchased from Cambridge Isotope Laboratory $\left(>97\right.$ atom $\%{ }^{18} \mathrm{O}_{2}$ ). Nitrogen used as diluent for the ${ }^{18} \mathrm{O}_{2}$ gas was also used for internal calibration of the mass spectrometer. The mean residence time of the reactor varied between 10 and $35 \mathrm{~ms}$, being a function of flow rate and temperature. Prior to measurements, the BE25 powder packed-bed was pre-treated at $1,073 \mathrm{~K}$ for $0.5 \mathrm{~h}$ under flowing synthetic air in order to remove possibly adsorbed
Fig. 1 Schematic representation of the pulse-response isotope exchange technique

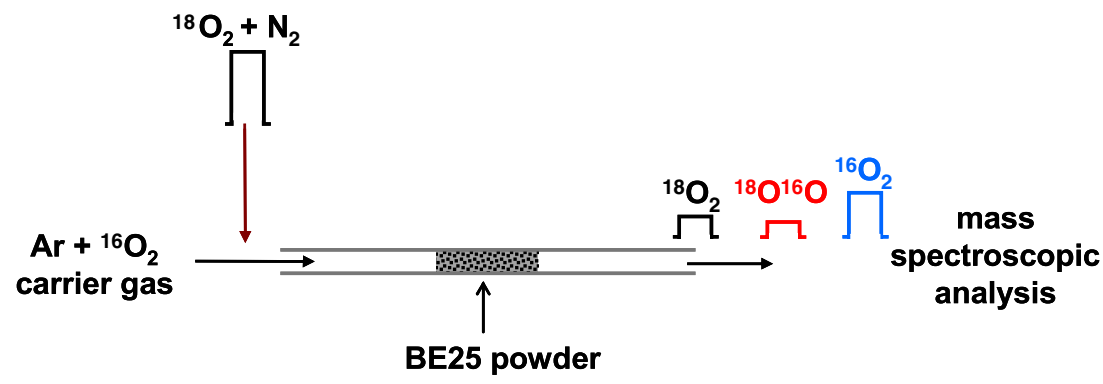


water and $\mathrm{CO}_{2}$, and subsequently cooled to room temperature at a rate of $5 \mathrm{~K} / \mathrm{min}$. The pulse isotopic exchange measurements were conducted in the $\mathrm{pO}_{2}$ range $0.1-0.95 \mathrm{~atm}$ from room temperature onwards up to $1,023 \mathrm{~K}$. The reactor was equilibrated $0.5 \mathrm{~h}$ at fixed $T$ and $p \mathrm{O}_{2}$ before and after data collection. Blank experiments revealed no exchange activity of the quartz microreactor.

The packed-bed microreactor was designed to approximate ideal plug flow behavior [16]. The isotopic exchange measurements were performed under conditions of negligible uptake of ${ }^{18} \mathrm{O}$ by the $\mathrm{BE} 25$ powder relative to the number of ${ }^{16} \mathrm{O}$ oxygen present in the oxide. The overall surface exchange rate, $\Re_{0}\left(\mathrm{molOm}^{-2} \mathrm{~s}^{-1}\right)$, was calculated from

$\Re_{0}=\frac{c_{\mathrm{g}}}{S_{\mathrm{r}} F} \ln \left(\frac{f_{\mathrm{i}}^{*}}{f_{\mathrm{e}}^{*}}\right)$

where $f_{\mathrm{i}}^{*}$ and $f_{\mathrm{e}}^{*}$ are the ${ }^{18} \mathrm{O}$ isotope fractions in the pulse at the inlet and exit of the reactor, respectively, $S_{\mathrm{r}}$ is the total BET surface area of the BE25 powder in the reactor, $F$ is the flow rate, and $c_{\mathrm{g}}=2 \mathrm{pO}_{2} / \mathrm{RT}$ is the concentration of oxygen in the gas phase. The flow rate $F$ can be equated to that at reference temperature: $F=F_{0} \cdot\left(T / T_{0}\right)$. The ${ }^{18} \mathrm{O}$ isotope gas phase fraction was calculated from the $f^{34}$ and $f^{36}$ mass fractions: $f^{*}=0.5 f^{34}+f^{36}$. Average values of three pulse experiments at a given $T$ and $p \mathrm{O}_{2}$ were taken for evaluation of the surface exchange rate.

\section{Results and discussion}

The XRD powder diffractogram (Fig. 2a) confirms the presence of a single cubic phase with a lattice parameter of $a=5.4736$ (6) $\AA$, which is in agreement with data reported in literature [17]. No evidence for the formation of second phases is found. The particle size distribution of the crushed BE25 ceramics as measured by laser light scattering is shown in Fig. 2b. The estimated average particle size, $d_{50}=0.4 \mu \mathrm{m}$, is much smaller than the critical thickness (see "Introduction" section), ensuring that the overall oxygen isotope equilibration is governed by the surface exchange kinetics rather than by bulk diffusion. The associated surface area calculated by the BET method using $\mathrm{N}_{2}(77 \mathrm{~K})$ gas adsorption data amounts to $0.2407(5) \mathrm{m}^{2} / \mathrm{g}$. The low value reflects the dense nature of the used BE25 powder, and is due to sintering prior to crushing the ceramic disk into a powder. The sintering step is made to avoid diffusion limitations in narrow pores during oxygen isotope equilibration.

Figure 3 shows the fractions of oxygen isotopomers in the gas phase volume associated with the pulse at the exit of the reactor as measured at different temperatures. It is seen that under the conditions maintained during the experiments, the exchange reaction starts around $773 \mathrm{~K}$. Above this temperature, the ${ }^{18} \mathrm{O}_{2}$ fraction decreases profoundly with increase of temperature, i.e., more ${ }^{18} \mathrm{O}$ is taken up by the sample, which is exchanged for ${ }^{16} \mathrm{O}$ as evidenced by the simultaneous increase of the ${ }^{16} \mathrm{O}_{2}$ fraction. The ${ }^{18} \mathrm{O}^{16} \mathrm{O}$ fraction remains comparatively low at all temperatures. The latter provides evidence that oxygen surface exchange on BE25 is limited by the dissociative adsorption of oxygen, as is further discussed below. The highest temperature of measurement $(1,023 \mathrm{~K})$ was chosen $50 \mathrm{~K}$ lower than the temperature of the pre-annealing in order to prevent microstructural changes to the powder.

The temperature dependence of the surface exchange rate, $\Re_{0}$, calculated using Eq. (1) is well described by an Arrhenius equation, as shown in Fig. 4. Also shown in this figure are results from previous studies [11-13, 18], showing good agreement with those from the present study. The
Fig. 2 a XRD pattern and b particle size distribution of BE25 powder used for the PIE experiments
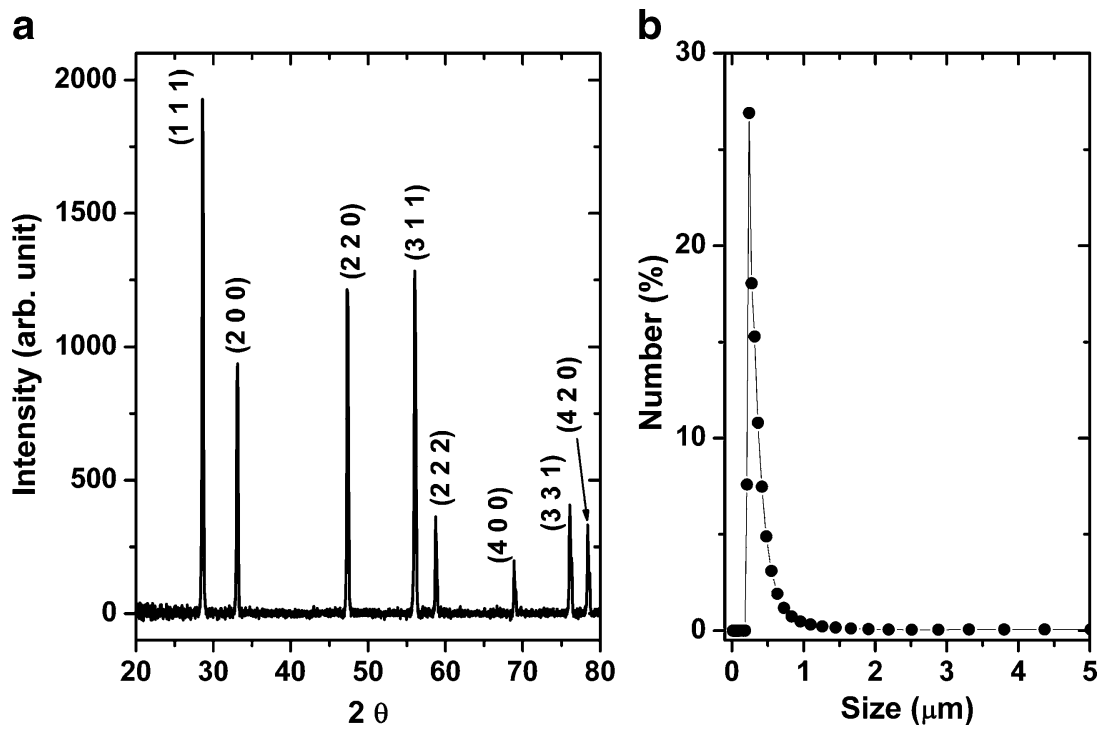


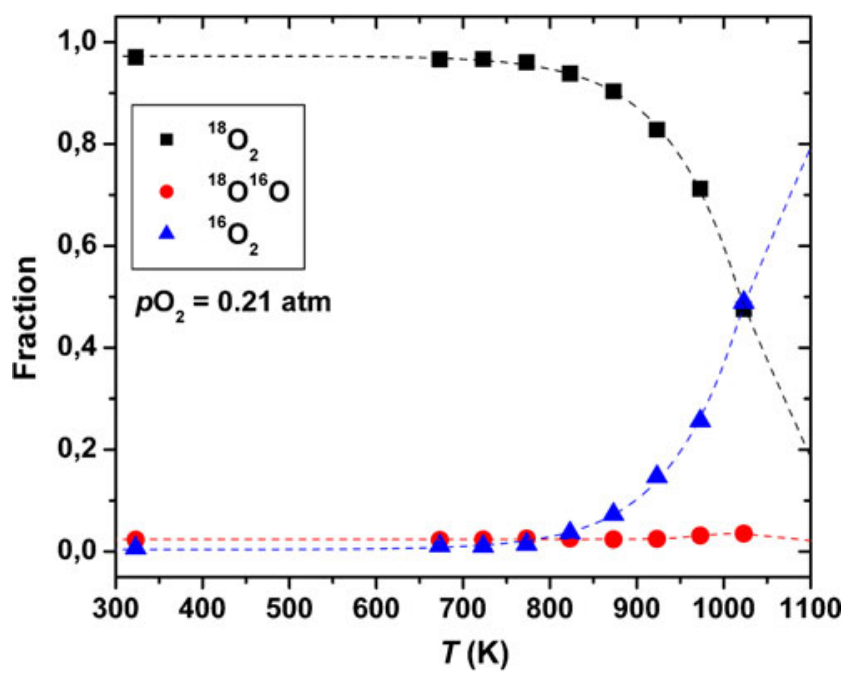

Fig. 3 Oxygen isotope fractions $\left({ }^{18} \mathrm{O}_{2},{ }^{18} \mathrm{O}^{16} \mathrm{O}\right.$, and $\left.{ }^{16} \mathrm{O}_{2}\right)$ as a function of temperature from PIE measurements at a nominal pressure of $0.21 \mathrm{~atm} p \mathrm{O}_{2}$. The drawn line is form model calculations, assuming constant activation energies for dissociative adsorption and incorporation over the entire temperature range. Error bars (for the $95 \%$ confidence interval of the mean) are smaller than the size of the symbols

calculated activation energy of 111 (3) $\mathrm{kJmol}^{-1}$ is in reasonable agreement with $130(5) \mathrm{kJmol}^{-1}$ calculated from data obtained by monitoring the time-dependent ${ }^{18} \mathrm{O}-{ }^{16} \mathrm{O}$ isotopic equilibration on a polished BE25 dense ceramic disk in a closed volume $[11,18]$. The surface exchange rates extracted from data of the depth-profiling studies displayed in Fig. 4 were recalculated using $\Re_{0}=k_{\mathrm{s}} c_{\mathrm{o}}$, where $k_{\mathrm{s}}\left(\mathrm{cms}^{-1}\right)$ is the surface exchange coefficient and $c_{\mathrm{o}}$ the concentration

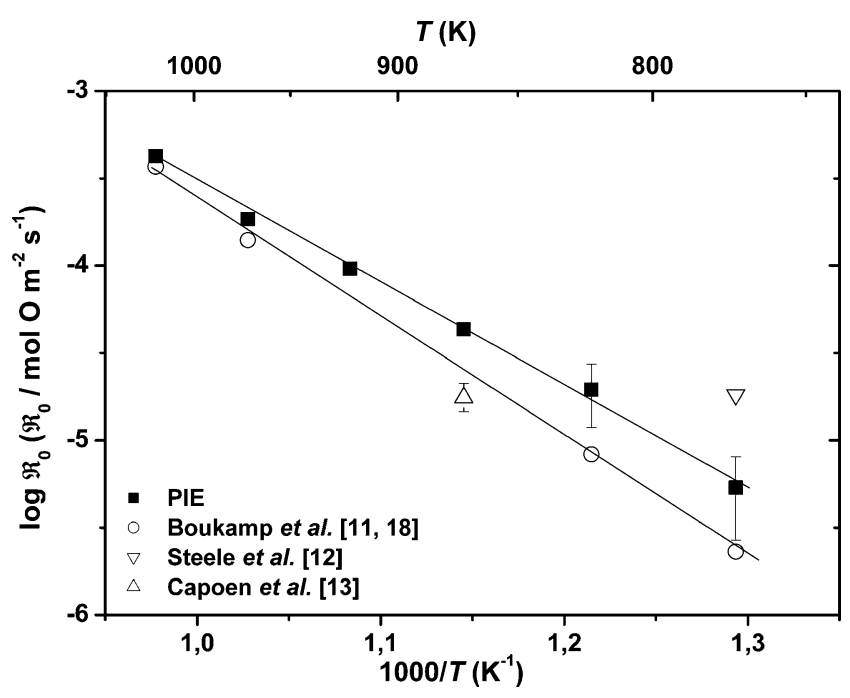

Fig. 4 Overall surface oxygen exchange rate for BE25 as a function of inverse temperature at a nominal pressure of $0.21 \mathrm{~atm} p \mathrm{O}_{2}$. Also shown are data from prior studies on BE25, obtained using time-dependent ${ }^{18} \mathrm{O}-{ }^{16} \mathrm{O}$ gas phase equilibration (Boukamp et al. $[11,18]$ ) and ${ }^{18} \mathrm{O}-{ }^{16} \mathrm{O}$ isotope exchange followed by depth profiling (Steele et al. [12] and Capoen et al. [13]) methods. Error bars represent the 95\% confidence interval of the mean; when not shown, these are smaller than the symbol size of oxygen ions in the oxide. It should be mentioned that it cannot be excluded that different preparation routes and preannealing temperatures, and departures from the targeted composition and/or contaminations may influence the magnitude of the surface exchange rate. Figure 5 shows the $p \mathrm{O}_{2}$ dependence of the overall surface exchange rate at different temperatures. At all four different temperatures, $\Re_{0}$ is found approximately proportional to $\left(p \mathrm{O}_{2}\right)^{n}$ with $n=0.5$, in nice agreement with results published previously [18].

The above results demonstrate the usefulness of PIE as a technique for acquisition of the oxygen surface exchange rate of fast oxygen-ionic conducting solids. The ${ }^{18} \mathrm{O}$-containing gas phase pulse passes through a 'sea of ${ }^{16} \mathrm{O}$ ' captured by the oxide powder bed, ensuring in this way that ${ }^{16} \mathrm{O}$ is returned to the gas phase upon every act of exchange. Measurements of the surface exchange rate are enabled as long as the effective time constant associated with isotopic exchange is of similar order as the time scale of the experiment, i.e., the residence time of the packedbed reactor. These are determined by oxide characteristics, such as the powder surface area, and by design and operating conditions, such as the length of the packedbed reactor, gas flow rate, and temperature, as can be inferred from Eq. (1). The design of the packed bed reactor to approximate plug flow conditions ensures that the distribution of residence times is small, and its average value simply can be calculated from the void volume of the reactor bed and the volumetric flow rate.

An advantage of methods based upon gas phase analysis to monitor ${ }^{18} \mathrm{O}-{ }^{16} \mathrm{O}$ isotope equilibration between the gas

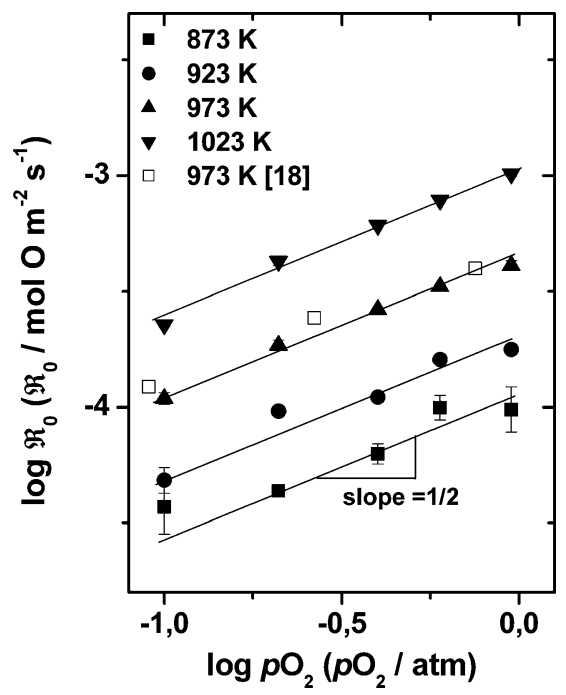

Fig. 5 Oxygen partial pressure dependence of the overall exchange rate on BE25 at different temperatures using PIE (filled symbol). Lines with slope $1 / 2$ are given to guide the eye. Error bars represent the $95 \%$ confidence interval of the mean; when not shown, these are smaller than the symbol size. The data from time-dependent ${ }^{18} \mathrm{O}-{ }^{16} \mathrm{O}$ gas phase equilibration on BE25 dense ceramic at $973 \mathrm{~K}$ reported by Boukamp et al. [18] (empty square symbol) is also included 

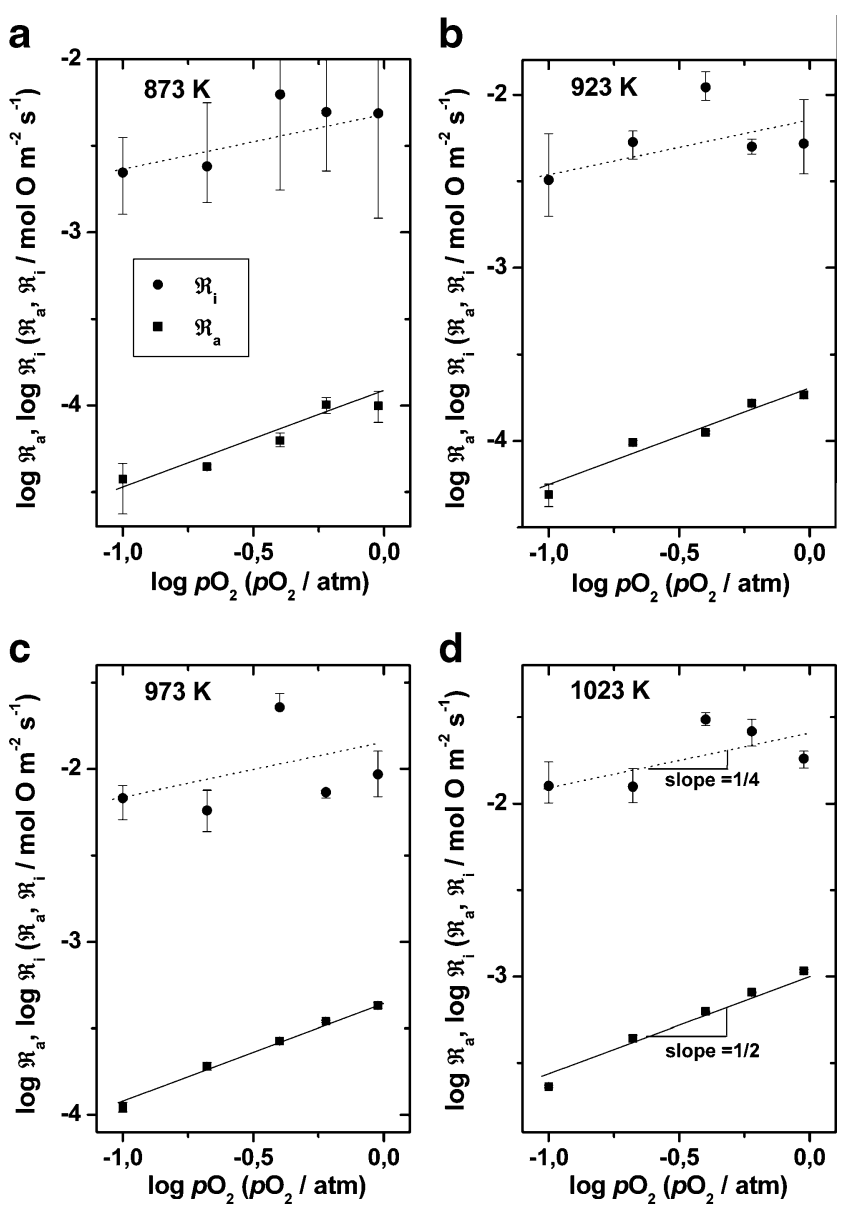

Fig. 6 The oxygen partial pressure dependence of the rates of dissociative adsorption ( $\Re_{\mathrm{a}}$, filled square) and oxygen incorporation $\left(\Re_{\mathrm{i}}\right.$, filled circle $)$ at different temperatures. Trendlines with slopes $1 / 2$ and $1 / 4$ are given to guide the eye. Error bars represent the $95 \%$ confidence interval of the mean; when not shown, these are smaller than the symbol size

phase and the oxide over that of depth profiling methods is that kinetic information can be extracted from the mass isotopomer distribution resulting from isotopic scrambling. The isotopic exchange reaction can be modeled as a sequence of two steps, dissociative adsorption occurring with a rate $\Re_{\mathrm{a}}$, and subsequent incorporation of oxygen in the oxide lattice with a rate $\Re_{\mathrm{i}}$,

step $1: \mathrm{O}_{2, \mathrm{~g}} \underset{\Re_{\mathrm{a}}}{\stackrel{\Re_{\mathrm{a}}}{\rightleftarrows}} 2 \mathrm{O}_{\mathrm{ad}}$

step $2: \mathrm{O}_{\mathrm{ad}} \underset{\Re_{\mathrm{i}}}{\stackrel{\Re_{\mathrm{i}}}{\rightleftarrows}} \mathrm{O}_{\text {lattice }}$

and includes oxygen adatoms $\mathrm{O}_{\mathrm{ad}}$ on the oxide surface as reaction intermediates. The ${ }^{18} \mathrm{O}$ isotope fraction at the oxide surface is balanced by the reversible rates $\Re_{\mathrm{a}}$ and $\Re_{\mathrm{i}}$ in conjunction with the isotopic compositions of the gas phase and oxide. The validity of the two-step scheme for modeling isotopic exchange relies on the assumption that isotopic scrambling can only occur after dissociative adsorption of oxygen on the oxide surface, excluding for example, the possibility that exchange may occur via a three-atom intermediate. In a quasi steady-state approximation for the isotopic exchange reaction, it follows

$\frac{1}{\Re_{0}}=\frac{1}{\Re_{\mathrm{a}}}+\frac{1}{\Re_{\mathrm{i}}}$

The overall exchange process can be conceptually viewed as a series of resistances. Expressions for the corresponding molar gas phase fractions of ${ }^{18} \mathrm{O}_{2},{ }^{16} \mathrm{O}^{18} \mathrm{O}$, and ${ }^{16} \mathrm{O}_{2}$ after exchange for a given time within the framework of the twostep scheme are presented elsewhere [16, 18]. Finally, it should be noted that the surface exchange reaction may involve a series of steps with several possible intermediates, e.g., $\mathrm{O}_{2}, \mathrm{O}_{2}^{2-}$, and $\mathrm{O}^{-}$. Both steps in the given two-step scheme still may represent a lumped reaction sequence with, for example, charge transfer and surface diffusion of atoms or ions as possible rate determining steps.

Figure 6a-d show the $p \mathrm{O}_{2}$ dependences of $\Re_{\mathrm{a}}$ and $\Re_{\mathrm{i}}$ for $\mathrm{BE} 25$ at different temperatures. The results indicate that the surface exchange reaction on BE25 is mainly limited by the rate of oxygen dissociative adsorption $\Re_{\mathrm{a}}$. This result can be deduced intuitively from the very small molar ${ }^{18} \mathrm{O}^{16} \mathrm{O}$ fraction observed during isotopic exchange, as illustrated in Fig. 3. At all temperatures, $\Re_{\mathrm{a}}$ appears proportional to $\mathrm{pO}_{2}{ }^{1 / 2}$, in obvious correspondence with the $p \mathrm{O}_{2}$ dependence of $\Re_{0}$, and found one to two orders of magnitude lower than $\Re_{\mathrm{i}}$.

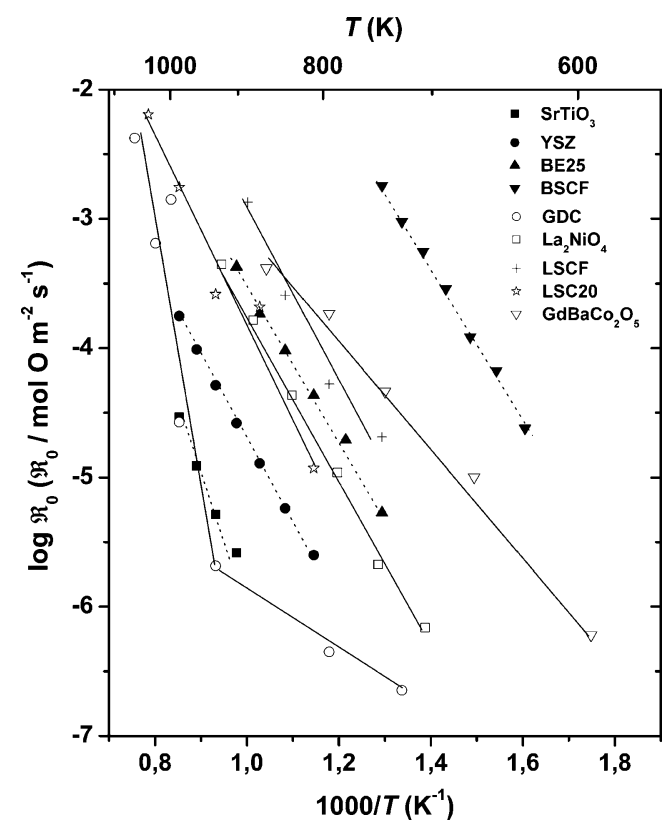

Fig. 7 Surface oxygen exchange rates for different oxides as a function of inverse temperature. $\mathrm{SrTiO}_{3}$ [21], $8 \mathrm{~mol} \%$ yttria-stabilized zirconia (YSZ) [16], BE25 (this study), $\mathrm{Ba}_{0.5} \mathrm{Sr}_{0.5} \mathrm{Co}_{0.8} \mathrm{Fe}_{0.2} \mathrm{O}_{3-\delta}$ (BSCF) [16], $10 \mathrm{~mol} \%$ gadolinia-doped $\mathrm{CeO}_{2}$ (GDC) [22], $\mathrm{La}_{2} \mathrm{NiO}_{4}$ [19], $\mathrm{La}_{0.6} \mathrm{Sr}_{0.4} \mathrm{Co}_{0.2} \mathrm{Fe}_{0.8} \mathrm{O}_{3-\delta}$ (LSCF) [23], $\mathrm{La}_{0.8} \mathrm{Sr}_{0.2} \mathrm{CoO}_{3-\delta}(\mathrm{LSC} 20)$ [24], and $\mathrm{GdBaCo}_{2} \mathrm{O}_{5}$ [25] 
The dissociative adsorption of oxygen on the surface can be represented by the successive reaction steps

$\mathrm{O}_{2}+\mathrm{e}^{\prime} \rightleftarrows \mathrm{O}_{2, \text { ad }}^{-} \quad K=\left[\mathrm{O}_{2, \text { ad }}^{-}\right] /\left[\mathrm{e}^{\prime}\right] p \mathrm{O}_{2}$

$\mathrm{O}_{2, \text { ad }}^{-}+\mathrm{e}^{\prime} \rightleftarrows 2 \mathrm{O}_{\text {ad }}^{-}$

where $K$ is the mass action constant of reaction (5). The observed $p \mathrm{O}_{2}{ }^{1 / 2}$ dependence of $\Re_{\mathrm{a}}$ can be explained by assuming that electron transfer to intermediate superoxide ions, $\mathrm{O}_{2}^{-}$, according to reaction (6), is the rate determining step in oxygen dissociative adsorption. Noting that the isotopic exchange experiment is carried out under conditions of equilibrium, $\Re_{\mathrm{a}}=\vec{\Re}_{\mathrm{a}}=\overleftarrow{\Re}_{\mathrm{a}}$, where $\vec{\Re}_{\mathrm{a}}=\vec{k}\left[\mathrm{O}_{2, \mathrm{ad}}^{-}\right]\left[\mathrm{e}^{\prime}\right]$ and $\overleftarrow{\Re}_{\mathrm{a}}=\overleftarrow{k}\left[\mathrm{O}_{\mathrm{ad}}^{-}\right]^{2}$ are the balanced forward and backward reaction rates, respectively, and $\vec{k}$ and $\overleftarrow{k}$ the corresponding rate constants. In deriving these kinetic equations, a low surface coverage of adsorbed oxygen species is assumed. To infer the $p \mathrm{O}_{2}$ dependence of $\Re_{\mathrm{a}}$, those of the concentrations entering these kinetic equations must be derived from preceding or succeeding equilibria. Under the experimental conditions, the bulk concentration of oxygen vacancies in BE25 is invariant with $p \mathrm{O}_{2}$. From defect chemical considerations, it follows that for $\mathrm{BE} 25$ the concentration of electrons varies according to $\left[\mathrm{e}^{\prime}\right] \propto p \mathrm{O}_{2}{ }^{-1 / 4}$. Substitution in the expression for $\vec{\Re}_{\mathrm{a}}\left(=\vec{k}\left[\mathrm{O}_{2, \mathrm{ad}}^{-}\right]\left[\mathrm{e}^{\prime}\right]=K \vec{k}\left[\mathrm{e}^{\prime}\right]^{2} p \mathrm{O}_{2}\right)$ shows that in accord with the experimental observations $\Re_{\mathrm{a}}$ is predicted to follow a $\mathrm{pO}_{2}{ }^{1 / 2}$ dependence. Reaction (6) may proceed via formation of a transient peroxide intermediate, $\mathrm{O}_{2}^{2-}$, which is known to be very unstable, before actual splitting of the adsorbed oxygen molecule into oxygen adatoms $\mathrm{O}_{\text {ad }}^{-}$.

As seen from Fig. 6a-d, the rate of oxygen incorporation $\Re_{\mathrm{i}}$ shows a weak dependence on $p \mathrm{O}_{2}$. The trend lines in these figures with a slope of $1 / 4$ should be considered with care given the large scatter in the obtained values of $\Re_{\mathrm{i}} . \Re_{\mathrm{i}}$ may either refer to a successive reaction step or to diffusion of $\mathrm{O}_{\mathrm{ad}}^{-}$or electron holes to the reaction site. More research is, however, needed for clarification.

Finally, Fig. 7 shows a graphical collection of data obtained for the surface oxygen exchange rate observed on various oxides using different techniques. It is seen that BE25 shows a comparatively high surface exchange rate, much higher than well-known solid electrolytes YSZ and gadolinia-doped ceria, and even higher than $\mathrm{La}_{2} \mathrm{NiO}_{4}$, which has been proposed as a cathode material for intermediate-temperature SOFCs [19, 20].

\section{Conclusions}

The results obtained from this study indicate that in the temperature and $p \mathrm{O}_{2}$ ranges investigated $\mathrm{BE} 25$ exhibits a comparatively high exchange rate, which is rate determined by the dissociative adsorption of oxygen. Electron transfer to intermediate superoxide ions is proposed as the rate determining step. The results further demonstrate the usefulness of pulse-based measurements of ${ }^{18} \mathrm{O}-{ }^{16} \mathrm{O}$ isotope exchange, which method employs a continuous flow packed bed microreactor, for kinetic and mechanistic studies of surface oxygen exchange of fast ionic conducting solids.

Acknowledgements Financial support from the Helmholtz Association of German Research Centres (Initiative and Networking Fund) through the MEM-BRAIN Helmholtz Alliance is gratefully acknowledged.

Open Access This article is distributed under the terms of the Creative Commons Attribution Noncommercial License which permits any noncommercial use, distribution, and reproduction in any medium, provided the original author(s) and source are credited.

\section{References}

1. Takahashi T, Esaka T, Iwahara H (1976) J Solid State Chem 16:317-323

2. Shuk P, Wiemhofer HD, Guth U, Gopel W, Greenblatt M (1996) Solid State Ionics 89:179-196

3. Sammes NM, Tompsett GA, Nafe H, Aldinger F (1999) J Eur Ceram Soc 19:1801-1826

4. Jiang NX, Wachsman ED, Jung SH (2002) Solid State Ionics 150:347-353

5. Verkerk MJ, Burggraaf AJ (1983) J Electrochem Soc 130:78-84

6. Verkerk MJ, Hammink MWJ, Burggraaf AJ (1983) J Electrochem Soc 130:70-78

7. Kruidhof H, Bouwmeester HJM, de Vries KJ, Gellings PJ, Burggraaf AJ (1992) Solid State Ionics 50:181-186

8. Jiang NX, Wachsman ED (1999) J Am Ceram Soc 82:3057-3064

9. Isaacs HS, Olmer LJ (1982) J Electrochem Soc 129:436-443

10. Wang DY, Nowick AS (1981) J Electrochem Soc 128:55-63

11. Boukamp BA, van Hassel BA, Vinke IC, de Vries KJ, Burggraaf AJ (1993) Electrochim Acta 38:1817-1825

12. Steele BCH, Kilner JA, Dennis PF, McHale AE, van Hemert M, Burggraaf AJ (1986) Solid State Ionics 18-9:1038-1044

13. Capoen E, Nowogrocki G, Chater RJ, Skinner SJ, Kilner JA, Mays M, Boivin JC, Mairesse G, Vannier RN (2006) Solid State Ionics 177:489-492

14. Bouwmeester HJM, Kruidhof H, Burggraaf AJ (1994) Solid State Ionics 72:185-194

15. Bouwmeester HJM, Kruidhof H, Burggraaf AJ, Gellings PJ (1992) Solid State Ionics 53-6:460-468

16. Bouwmeester HJM, Song C, Zhu J, Yi J, van Sint Annaland M, Boukamp BA (2009) Phys Chem Chem Phys 11:9640-9643

17. Verkerk MJ, Keizer K, Burggraaf AJ (1980) J Appl Electrochem 10:81-90

18. Boukamp BA, Vinke IC, de Vries KJ, Burggraaf AJ (1989) Solid State Ionics 32-3:918-923

19. Skinner S, Kilner J (2000) Solid State Ionics 135:709-712

20. Sayers R, Liu J, Rustumji B, Skinner SJ (2008) Fuel Cells 8:338-343

21. Yoo CY, Bouwmeester HJM (2010) (in press)

22. Lane JA, Kilner JA (2000) Solid State Ionics 136:927-932

23. Esquirol A, Kilner J, Brandon N (2004) Solid State Ionics 175:63-67

24. De Souza RA, Kilner JA (1999) Solid State Ionics 126:153-161

25. Tarancon A, Skinner SJ, Chater RJ, Hernandez-Ramirez F, Kilner JA (2007) J Mater Chem 17:3175-3181 